\title{
NIEUWE SCHENKING JAPANSE PRENTEN VOOR HET RIJKSMUSEUM AMSTERDAM
}

Het prentenkabinet van het Rijksmuseum heeft met ongeveer 3000 Japanse prenten een van de grootste openbare collecties in Nederland op dat gebied onder haar hoede. Dat de collectie nog steeds groeit, is voor een groot deel te danken aan de vele particuliere schenkingen door de jaren heen. Onlangs ontving het museum vijf prenten uit de verzameling van mr. M.P. Dorhout (1934-2012). De heer Dorhout verzamelde Japanse prenten met afbeeldingen van de berg Fuji. Zijn verzameling groeide uit tot meer dan 300 prenten uit de $18^{\mathrm{e}}$ tot en met de $20^{\mathrm{e}}$ eeuw, waarvan een klein deel in het jaar 2000 werd gepubliceerd. ${ }^{1}$ Uit deze bijzondere collectie kreeg het Rijksprentenkabinet drie prenten van Keisai Eisen (1790-1848), een waaierprent van Utagawa Kuniyoshi (1797-1861) en een prent van Suzuki Harunobu (1724-1770).

\section{Harunobu}

De prent van Harunobu (afb. 1) toont een man en een vrouw te paard aan de waterkant. De man heeft in zijn linkerhand de teugels van het paard vast en in zijn rechterhand een pijp. Ook de vrouw, in amazonezit op het paard, heeft een pijp in haar hand. Het tweetal lijkt onderweg even te zijn gestopt om de besneeuwde Fuji te bewonderen die zich op de achtergrond hult in een dik wolkendek. Deze afbeelding is een mitate, een parodie, op een verhaal

Afb. 1

Suzuki Harunobu, man en vrouw te paard bewonderen de berg Fuji, uitgeven door Tsutaya Kichizô in 1768, kleurenhoutsnede, Japan, Rijksmuseum Amsterdam, inv.nr. RP-P-2014-29-3. Schenking van de heer M.P. Dorhout, Groningen. uit de Ise monogatari ('Het verhaal van Ise'). ${ }^{2}$ In het oorspronkelijke verhaal wordt een man, geen vrouw zoals hier is afgebeeld, te paard vergezeld door één of twee begeleiders. ${ }^{3}$ Dat beide figuren in deze prent een pijp vasthouden, is een ongebruikelijk en interessant detail. Wanneer het wolkendek beter wordt bekeken, lijkt het wolkje halverwege de rechterzijde van de berg de uitgeblazen rook van de vrouw te zijn. Wellicht wordt hier subtiel de spot gedreven met de Fuji als toeristische trekpleister, door het te laten overkomen alsof de wolken rond de berg het gevolg zijn van de vele rokende reizigers die destijds even stilstonden om de Fuji te bewonderen.

\section{Kuniyoshi}

De Kuniyoshi prent (afb. 2) toont de Fuji zonder wolken, in de schemering. Afgebeeld is de acteur Iwai Kumesaburô III terwijl hij mijmerend onder een bloeiende kersenboom van het uitzicht geniet. Ook hier wordt met het beeld gespeeld: op de prent, bedoeld om in een waaier gemonteerd te worden, is de acteur afgebeeld met zelf ook een waaier in zijn hand.

\section{Eisen}

Van de drie geschonken Eisen prenten behoren er twee tot dezelfde,

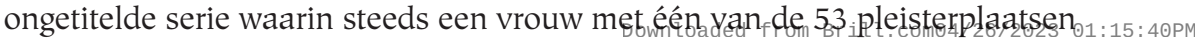




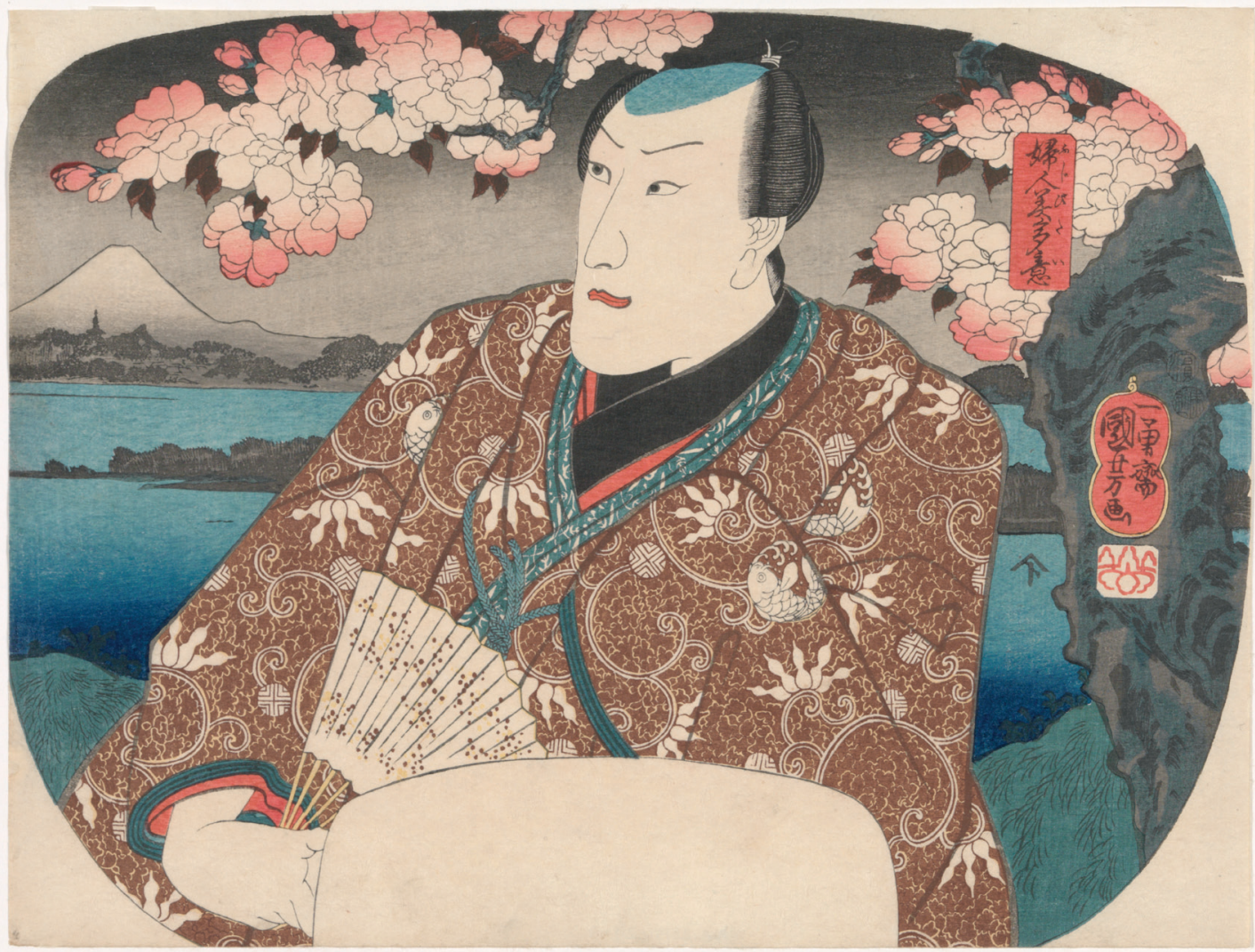

Afb. 2 (boven) Utagawa Kuniyoshi, waaierprent met acteur, uitgeven door Enshûya Matabei in 1850, kleurenhoutsnede, Japan, Rijksmuseum Amsterdam, inv.nr.

RP-P-2014-29-4.

Schenking van de heer M.P. Dorhout, Groningen.

Afb. 3 (rechts) Kitagawa Eisen, vrouw met insectenkooitje (Okitsu 18), uitgeven door Tsutaya Kichizô in 1830, kleurenhoutsnede, Japan, Rijksmuseum Amsterdam, inv.nr. RP-P-2014-29-2.

Schenking van de heer M.P. Dorhout, Groningen. van de Tôkaidô (de belangrijkste weg in Japan destijds) is afgebeeld. De prent met de titel Okitsu 18 toont een courtisane met in haar handen een insectenkooitje (afb. 3). Op de achtergrond zijn reizigers afgebeeld onderweg naar de pleisterplaats Okitsu. De tweede prent uit deze serie is getiteld Mitsuke 29 (afb. 4). We zien een vrouw zittend bij een komfoor, terwijl ze een brief leest. Op de achtergrond zijn reizigers zichtbaar, klaar om per boot de rivier over te steken naar het dorp Mitsuke aan de voet van de Fuji.

De derde prent is een gezicht op de Fuji vanaf Nihonbashi, omsloten in een rand van 'Westerse' letters (afb. 5). Het woord 'HoLLAND' of 'HoLLANDE' springt meteen in het oog, en ook het VOC symbool is een aantal maal gebruikt. Hoewel de rand zeer waarschijnlijk niet door Eisen is ontworpen maar door de uitgever is toegevoegd, laat ook het landschap een duidelijk Westerse invloed zien door het gebruik van lineair perspectief. ${ }^{4}$

Kortom, vijf interessante prenten die een prachtige aanvulling vormen op de collectie van het Rijksprentenkabinet. Wanneer u deze prenten, of een ander deel van de collectie wilt bestuderen, nodig ik u van harte uit in de studiezaal van het Rijksmuseum. ${ }^{5}$ 


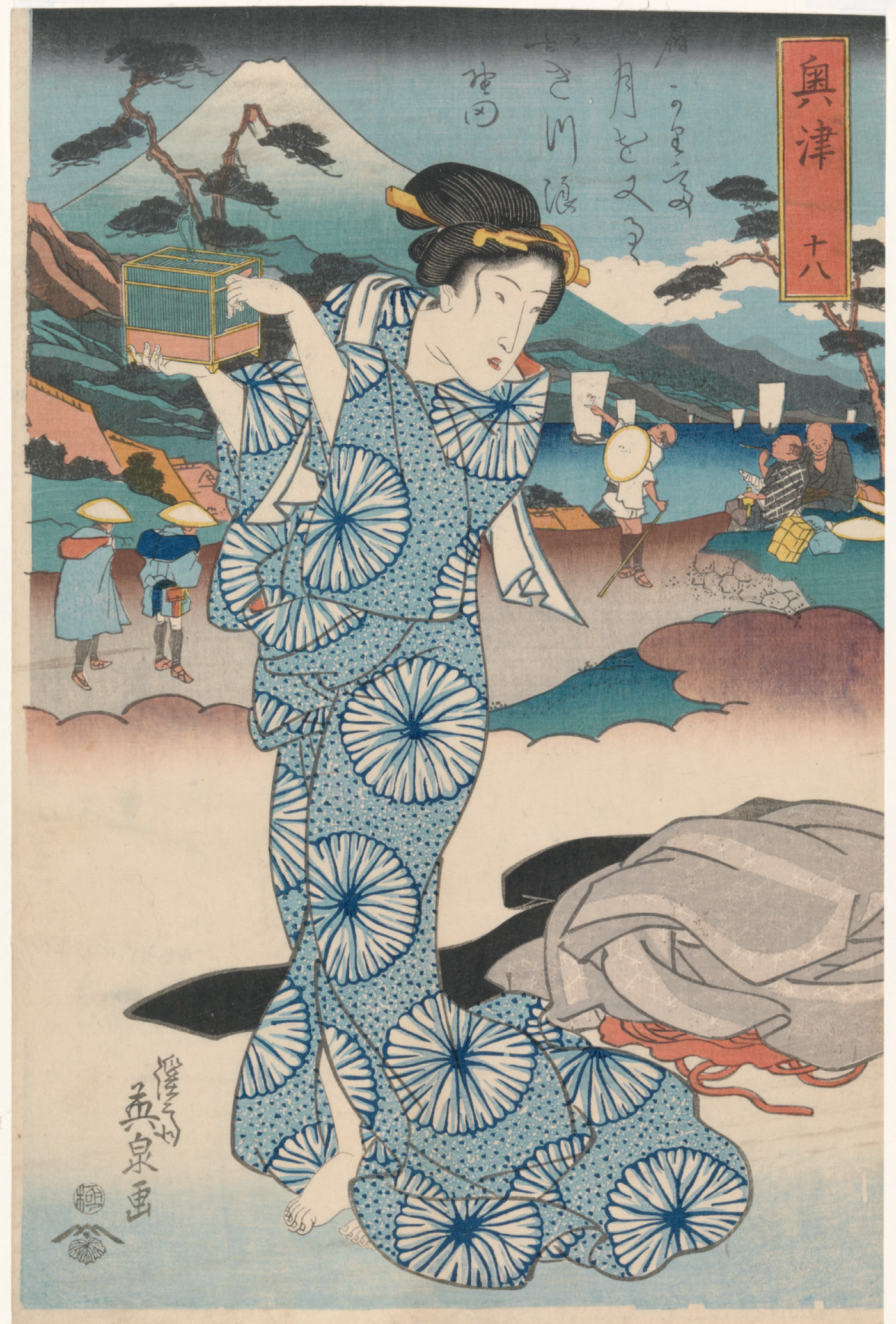




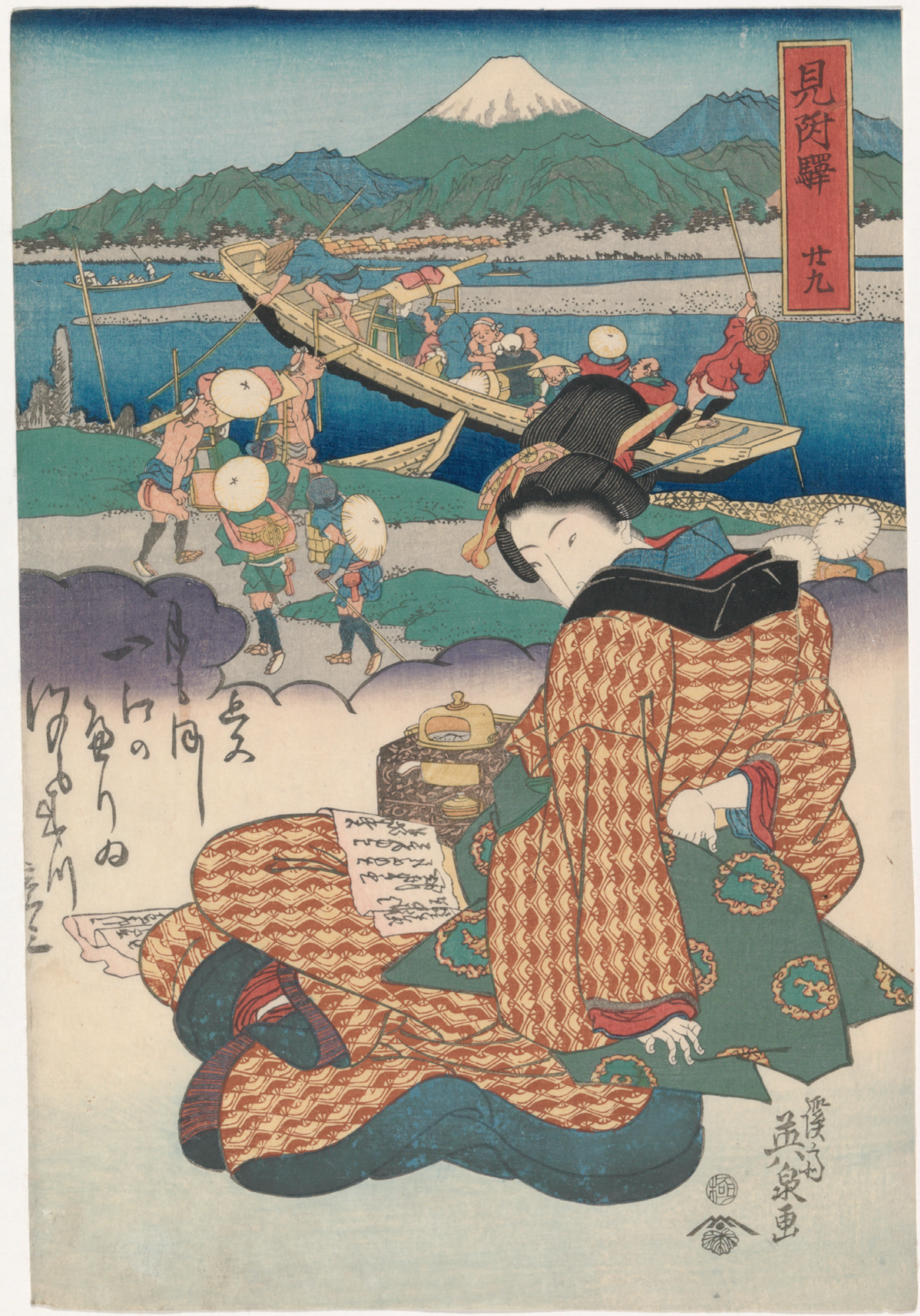




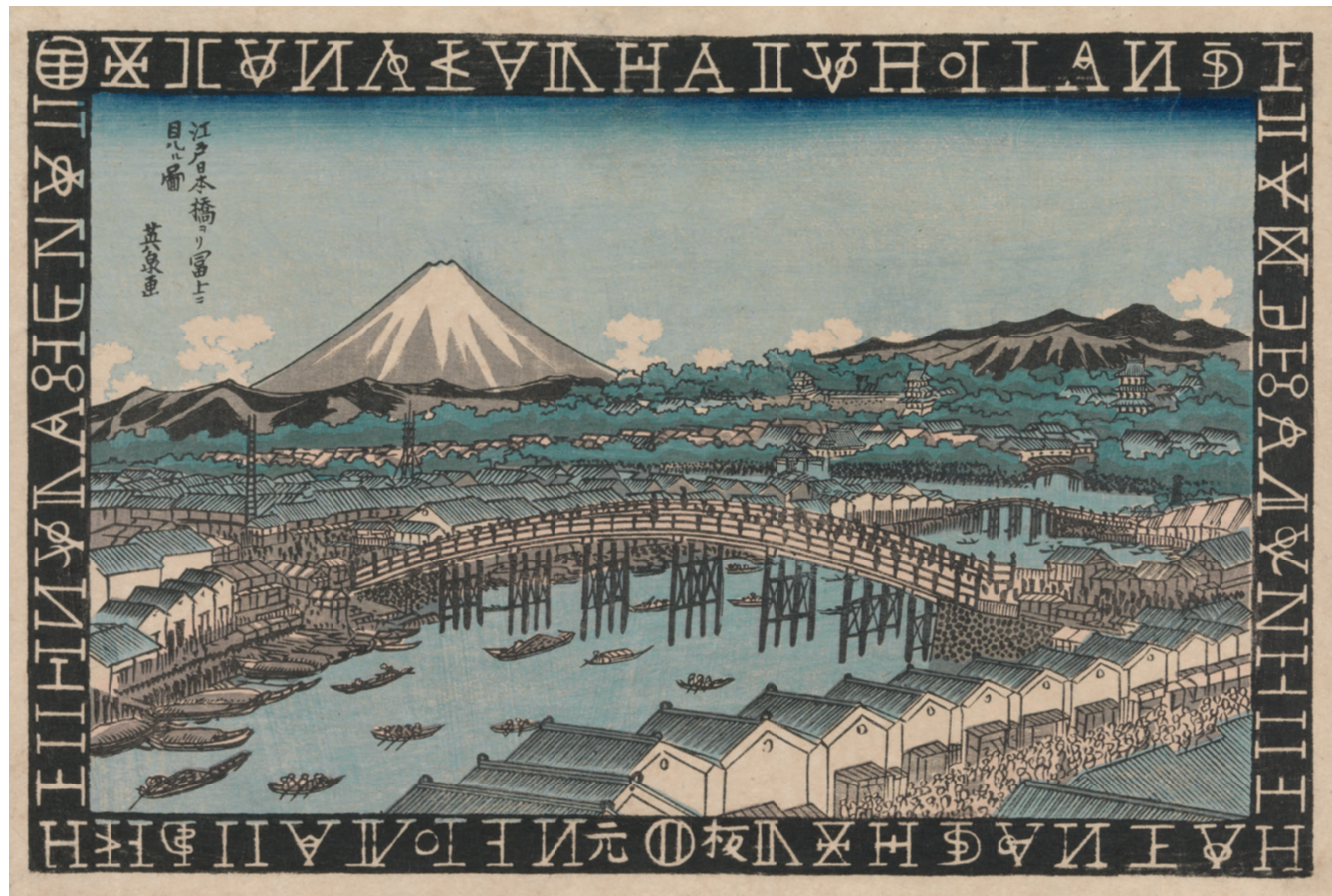

Afb. 4 (links)

Kitagawa Eisen, brief

lezende vrouw bij

komfoor (Mitsuke

29), uitgeven door

Tsutaya Kichizô in 1830,

kleurenhoutsnede,

Japan, Rijksmuseum

Amsterdam, inv.nr.

RP-P-2014-29-1.

Schenking van de

heer M.P. Dorhout,

Groningen.

Afb. 5 (boven)

Kitagawa Eisen, de berg

Fuji vanaf Nihonbashi

in Edo (Edo Nihonbashi

yori Fuji o miru zu),

uitgeven door Ezakiya

Kichibei in 1827 ,

kleurenhoutsnede, Japan, Rijksmuseum

Amsterdam, inv.nr.

RP-P-2014-29-5.

Schenking van de

heer M.P. Dorhout,

Groningen.
- Marije Jansen is conservator Japanse prenten bij het Rijksmuseum Amsterdam. Ze studeerde Japanse taal en cultuur aan de Universiteit Leiden, waarna ze zich specialiseerde in Japanse prentkunst. Daarnaast studeerde ze Kunstgeschiedenis aan de Universiteit van Amsterdam. Marije is verantwoordelijk voor de collectie Japanse prenten en geïllustreerde boeken en heeft een speciale belangstelling voor de verzamelgeschiedenis van Japanse prenten in Nederland.

\section{Literatuur}

Daan Kok, 'Keisai Eisen and his landscapes with Dutch letter borders', Andon 79 (2005), pp. 23-32.

Keiko Nakamachi, Henry Smith en Miriam Wattles, 'Ukiyo-e Memories of Ise Monogatari', Impressions 22 (2000), pp. 54-85.

Chris Uhlenbeck en Merel Molenaar, Mount Fuji - Sacred mountain of Japan, Hotei Publishing, Leiden, 2000.

\section{Noten}

1. Uhlenbeck en Molenaar 2000.

2. De Ise Monogatari is een verzameling gedichten en aanvullende teksten uit de $9 \mathrm{e}$ eeuw over het amoureuze leven van een anonieme man, naar verluidt de dichter Ariwara no Narihira (ca. 825-880), die vermoedelijk ook de auteur van het werk is.

3. Zie voor gedetailleerde uitleg over mitate, en specifiek dit exemplaar van Harunobu, in Ise Monogatari prenten: Nakamachi, Smith en Wattles 2000: 54-85.

4. Zie voor het gebruik van dit soort letterranden: Kok 2005: 22-32.

5. De collectie prenten van het Rijksmuseum Amsterdam is op afspraak te bestuderen in de studiezaal van het Rijksmuseum (open: ma t/m zat 10-17 uur contact; studiezaal@rijksmuseum.nl). 


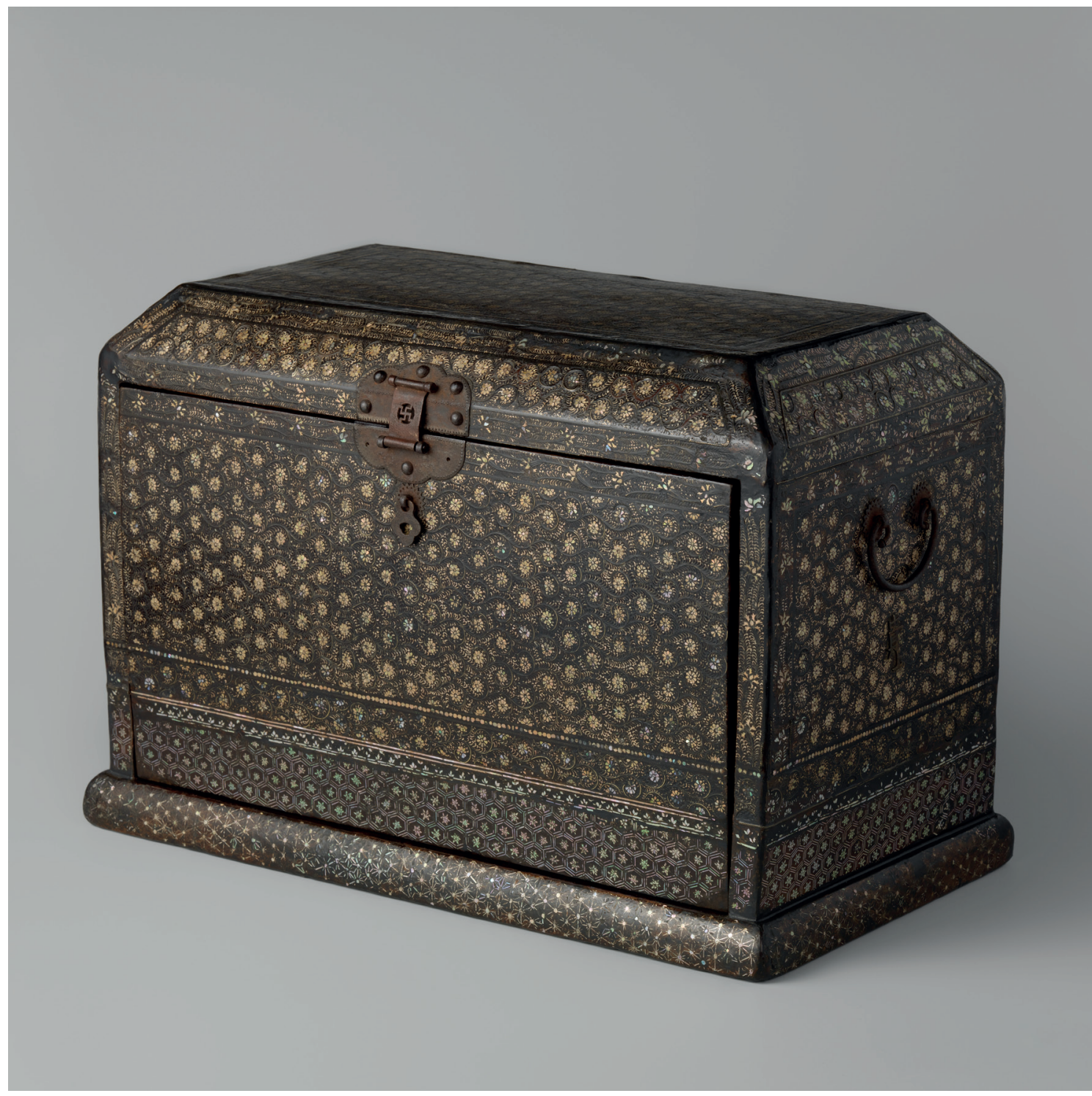

Afb. 1

De soetrakist voor

restauratie, hout, lak,

parelmoer, metaal-draad,

34 x 49,5 x 27,5 cm., Korea,

Koryo-periode (918-1392),

Rijksmuseum Amsterdam,

inv.nr. AK-MAK-178.

Bruikleen van de VVAK,

verwerving 1972.

Foto: Rijksmuseum

Amsterdam. 